\title{
Clinical features and outcome of multiple primary malignancies involving hepatocellular carcinoma: A long-term follow-up study
}

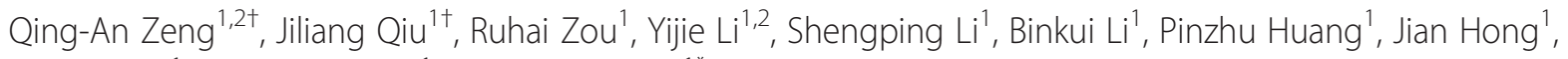
Yun Zheng ${ }^{1}$, Xiangming Lao ${ }^{1}$ and Yunfei Yuan ${ }^{1^{*}}$

\begin{abstract}
Background: The prolonged survival of individuals diagnosed with cancer has led to an increase in the number of secondary primary malignancies. We undertook to perform a definitive study to characterize and predict prognosis of multiple primary malignancies (MPM) involving hepatocellular carcinoma (HCC), due to the scarcity of such reports.

Methods: Clinicopathological data were analyzed for 68 MPM patients involving HCC, with 35 (target group) underwent curative liver resection. Additional 140 HCC-alone patients with hepatectomy were selected randomly during the same period as the control group.

Results: Of the 68 patients with extrahepatic primary malignancies (EHPM), 22 were diagnosed synchronously with HCC, and 46 metachronously. The most frequent EHPM was nasophargeal carcinoma, followed by colorectal and lung cancer. Univariate analysis demonstrated that synchronous $(P=0.008)$ and non-radical treatment for EHPM $(P<0.001)$ were significant risk factors associated with poorer overall survival (OS). While, Cox modeling revealed that the treatment modality for EHPM, but not the synchronous/metachronous determinant, was an independent factor for OS, and that therapeutic option for HCC was an independent factor for HCC-specific OS. Moreover, no HCCspecific overall and recurrence-free survival benefit were observed in the control group when compared with that of the target group $(P=0.607, P=0.131$, respectively).

Conclusions: Curative treatment is an independent predictive factor for OS and HCC-specific OS, and should been taken into account both for synchronous and metachronous patients. MPM patients involving HCC should not be excluded from radical resection for HCC.
\end{abstract}

Keywords: Neoplasm, Multiple primary, Extrahepatic, Hepatocellular carcinoma, Prognosis

\section{Background}

Hepatocellular carcinoma (HCC) ranks as the fifth most common tumor and third leading cause of global cancerrelated mortality [1]. The improvement in early diagnosis and the advances in treatment, including new targeted therapy, result to greatly improve the prognosis of HCC patients. Consequently, there is an increasing need to consider the development of multiple primary malignancies (MPM), which may influence the treatment for HCC.

\footnotetext{
* Correspondence: yuanyf@mail.sysu.edu.cn

${ }^{\dagger}$ Equal contributors

'State Key Laboratory of Oncology in South China/Department of Hepatobiliary Oncology, Sun Yat-Sen University Cancer Center, 651 Dongfeng Road East, Guangzhou, Guangdong 510060, China

Full list of author information is available at the end of the article
}

Although the incidence of MPM has begun to rise during the past decade, knowledge of the clinical features and outcomes of MPM remains limited. From a clinical viewpoint, it is important to determine whether cancersurvivors are predisposed to suffer some specific tumor types, and whether the prognosis of MPM patients including HCC differ from those afflicted with liver-limited malignancy in term of HCC-specific survival. Moreover, subsequent malignancies may not only be attributable to prior cancer-related treatment, but may also mirror the impact of therapy-related factors, shared etiologies, host immune responses, environmental exposures, and combination effects of the gene-environment. Clearly, as the treatment for the first cancer might limit therapeutic

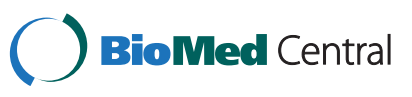


potential upon diagnosis of a secondary cancer, more information regarding the MPM patients with HCC is needed to facilitate the establishment of therapeutic strategies for those patients.

To the best of our knowledge, only two papers examined the clinicopathological factors of MPM with more than 20 patients [2,3], who had received radical hepatectomy for primary HCC, have been published within the last 20 years. Although small sample-sized studies were performed in Japan [4,5], Taiwan [6], and Western countries [7], none of them were from Mainland China, an area with a high incidence of HCC $(>20$ annual cases per $10^{5}$ people) [8]. This retrospective study was designed to characterize MPM patients, to explore long-term prognosis, and to investigate the impact of extrahepatic primary malignancy (EHPM) on survival of HCC in China.

\section{Methods}

\section{Definition of second primary malignancy}

A second primary neoplasm was defined according to IARC (International Agency for Research on Cancer) rules $[9,10]$, as follows: 1 . The existence of two or more primary cancers does not depend on time; 2. Both tumors are confined to primary sites, and no direct connections between the tumors exist; 3 . One tumor should only be recognized in an organ or a pair of organs or tissue (as defined by the code of the International Classification of Diseases (ICD)); 4. Rule 3 does not apply if tumors in an organ are of a different histology; 5. Be different in histological type when diagnosis of pathology available.

\section{Patients}

Between Jan. 1989 and Apr. 2008, 68 patients experienced MPM involving HCC in the Sun Yat-Sen University Cancer Center, and a total of 2841 HCC-alone patients received hepatectomy during the same period. Among the 68 MPM patients, 35 (51.5\%) underwent radical hepatectomy and were defined as the target group. To investigate the influence of EHPM on HCC-specific survival, 140 surgical HCC-alone patients (four times of the target group) were randomly selected from 2841 patients as the control group. The definitions for synchronous and metachronous (interval $>6$ months) have also been addressed in several previous studies [11-13]. HCC was noninvasively diagnosed on the basis of the typical radiological features on ultrasonography, computed tomography $(\mathrm{CT})$, magnetic resonance imaging (MRI), and a combination of alpha-fetoprotein (AFP) levels [14]. Positron emission tomography scan with ${ }^{18} \mathrm{~F}$-fluorodeoxyglucose was carried out since Oct 2005 in our center, which was performed if a secondary primary cancer was suspected, and 16 patients were found using this method.
Of note, histopathology from biopsy or liver resection remains the golden diagnostic standard. Patients who met the diagnosis criteria of autoimmune hepatitis [15] or cholangiocarcinoma were excluded. All the recruited patients gave written informed consent before examination and treatment. The study protocol was approved by the Ethics Committee of Sun Yat-Sen University Cancer Center and conformed to the ethical guidelines of the Helsinki Declaration.

Overall survival (OS) was calculated between the date of the first primary treatment and date of death or last follow-up of either the first or the subsequent malignancy. HCC-specific OS was defined as the interval from the date of diagnosis of HCC to the patient's death of related HCC, or last follow-up, whileas HCC-specific recurrence-free survival (RFS) was defined as the interval from the date of diagnosis of HCC to the tumor recurrence or last contact with the patient if recurrence did not occur. Curative therapy was defined as treatment for the EHPM with intent to cure according to different tumor classification, e.g., surgery for colorectal, gastric, lung, esophagus, cervical, breast, thyroid, oral, and renal cancer, or radiochemotherapy for nasopharyngeal cancer and non-Hodgkin lymphoma. Supportive therapy was defined a treatment that encompassed nonspecific therapeutic factors for tumor, such as facilitating affect expression. And the palliative treatment was an intermediate one between them.

\section{Statistical analysis}

Descriptive statistics are expressed as mean \pm standard deviation. The $T$-test, chi-square test or Fisher's exact test, where appropriate, were used for univariate comparisons. For univariate survival analysis, plots were generated using the Kaplan-Meier method. A Multivariate model was built to evaluate the risk associated with prognostic parameters. Differences were considered significant when $P<0.05$. All statistical analyses were performed using SPSS version 16.0 statistical software package (SPSS, Inc, Chicago, IL). The study was censored on Jul 30, 2011.

\section{Results}

\section{Patient characteristic}

Of the 68 patients, 67 (98.5\%) had double cancers and 1 $(1.5 \%)$ suffered from triple cancers. The most frequent site preceding or following HCC was nasopharynx (11/68, $16.2 \%)$, followed by colorectal $(10 / 68,14.7 \%)$, lung $(6 / 68$, $8.8 \%)$, skin, gastric, esophagus, cervical, breast, thyroid, oral, urinary bladder, and renal cancer as well as nonHodgkin lymphoma. The different tumor types and therapeutic option for EHPM are presented in Table 1. Of the 68 patients with EHPMs, 22 were diagnosed synchronous with HCC, and 46 belonged to the metachronous group. To stratify the metachronous group clearly, 35 patients 
Table 1 Locations of extrahepatic primary cancers implicating hepatocellular carcinoma

\begin{tabular}{|c|c|c|c|}
\hline $\begin{array}{l}\text { Site of } \\
\text { extrahepatic } \\
\text { primary cancer }\end{array}$ & $\begin{array}{l}\text { Synchronous } \\
\text { group }(n=22)\end{array}$ & $\begin{array}{l}\text { Metachronous } \\
\text { group }(n=46)\end{array}$ & $\begin{array}{c}\text { Total } \\
(n=68)\end{array}$ \\
\hline Head \& neck & 8 (36.4\%) & $15(32.6 \%)$ & $23(33.8 \%)$ \\
\hline nasopharynx & $2\left(1^{R} 1^{S}\right) *$ & $9\left(9^{R}\right)$ & 11 \\
\hline tonsil & $1\left(1^{\mathrm{C}}\right)$ & 0 & 1 \\
\hline larynx & $1\left(1^{\mathrm{C}}\right)$ & 0 & 1 \\
\hline vocal cord & $1\left(1^{S}\right)$ & $1\left(1^{\mathrm{O}}\right)$ & 2 \\
\hline mouth & 0 & $1\left(1^{\circ}\right)$ & 1 \\
\hline tongue & $2\left(1^{C} 1^{S}\right)$ & $1\left(1^{\circ}\right)$ & 3 \\
\hline gingiva & 0 & $1\left(1^{\circ}\right)$ & 1 \\
\hline soft palate & $1\left(1^{S}\right)$ & 0 & 1 \\
\hline thyroid gland & 0 & $2\left(2^{\mathrm{P}}\right)$ & 2 \\
\hline Digestive system & $8(36.4 \%)$ & $10(21.7 \%)$ & $18(26.5 \%)$ \\
\hline esophagus & $1\left(1^{S}\right)$ & $4\left(3^{O} 1^{\mathrm{C}}\right)$ & 5 \\
\hline stomach & $2\left(2^{\circ}\right)$ & $1\left(1^{9}\right)$ & 3 \\
\hline colorectal & $5\left(5^{9}\right)$ & $5\left(5^{\circ}\right)$ & 10 \\
\hline Urogenital system & $1(4.5 \%)$ & 5 (10.9\%) & $6(8.8 \%)$ \\
\hline prostate & 0 & $1\left(1^{\bigcirc}\right)$ & 1 \\
\hline urinary bladder & $1\left(1^{9}\right)$ & $1\left(1^{9}\right)$ & 2 \\
\hline kidney & 0 & $2\left(1^{O} 1^{C}\right)$ & 2 \\
\hline ovary & 0 & $1\left(1^{9}\right)$ & 1 \\
\hline Others & $5(22.7 \%)$ & $16(34.8 \%)$ & 20 (29.4\%) \\
\hline lung & $2\left(1^{C} 1^{S}\right)$ & $4\left(1^{O} 2^{C} 1^{R}\right)$ & 6 \\
\hline breast & 0 & $4\left(4^{\mathrm{O}}\right)$ & 4 \\
\hline skin & $1\left(1^{9}\right)$ & $4\left(4^{\mathrm{O}}\right)$ & 5 \\
\hline $\begin{array}{l}\text { Non Hodgkin's } \\
\text { lymphoma }\end{array}$ & $1\left(1^{R}\right)^{\dagger}$ & $3\left(3^{C}\right)$ & 3 \\
\hline melanoma & 0 & $1\left(1^{\mathrm{O}}\right)$ & 1 \\
\hline Soft tissue tumor & $1\left(1^{\circ}\right)$ & 0 & 0 \\
\hline
\end{tabular}

${ }^{*}$ number ${ }^{\text {treatment }}$ Treatment include: $\mathrm{O}$ operation; $\mathrm{R}$ radiotherapy; $\mathrm{C}$

chemotherapy; $\mathrm{S}$ supportive treatment.

${ }^{+}$The patient suffered the third primary malignancy, acute monocytic leukemia.

occurred prior to HCC (prior group), and 11 posterior to HCC (post group). In addition, 18 patients had HCC diagnosed before EHPM, 12 patients had HCC and EHPM during the same hospital admission, and the remaining 38 were diagnosed with EHPM occurring ahead of HCC, with 19 patients underwent hepatectomy.

In the entire study, 61 cancer patients were male and 7 were female. Hepatitis B surface antigen ( $\mathrm{HBsAg}$ ) was detected in $66.2 \%(45 / 68)$ patients, while hepatitis C antibody was negative in any of the patients. Cirrhosis was present in $75.0 \%(51 / 68)$ of the cases. HCC patients were diagnosed through the following routes: 35 were diagnosed on the basis of histology via hepatectomy, 30 by standard clinical and imaging criteria combined with AFP levels, and 3 cases underwent biopsies following an uncertain clinical diagnosis. As demonstrated in Figure 1, 45.7\% (21/46) of the metachronous patients experienced their secondary cancer within 2 years of the initial cancer diagnosis, while $55.2 \%(30 / 46)$ of the patients were diagnosed within 5 years, with a clear predominance in the prior group. The diagnostic intervals between the two cancers ranged from 6.5 months to 14.8 years in the metachronous patients (51.0 \pm 47.4 months). No significant difference was observed in the interval time between the post and prior groups ( $51.3 \pm 50.4$ vs. $50.2 \pm 37.8, P=0.946)$.

The median follow-up time was 7.8 years, with a range of 3.2 to 16.1 years. During the follow-up, 32 (47.1\%) patients were still alive, while $29(42.6 \%)$ patients died of HCC-related causes, 4 (5.9\%) of EHPM-related causes, and $3(4.4 \%)$ of unclear causes.

Of the $68 \mathrm{HCC}$ patients with a history of EHPM, 35 underwent liver resection, 7 local ablation considering severe cirrhosis, 14 tranarterial chemoembolization, and 11 supportive treatment. Moreover, of the 68 EHPM patients, 54 received curative therapy for EHPM, 8 palliative therapy, and 6 supportive treatment (Table 2). No significant difference regarding gender, age, ChildPugh grading, AFP, GGT level, TNM stage, and treatment for HCC were observed in the synchronous and metachronous groups (Table 2). Interestingly, the rate of patients received radical treatment for EHPM in the metachronous group was higher than that of the synchronous group $(P<0.001$, Table 2$)$.

\section{Univarite and multivariate analysis of prognosis}

The actuarial 1-, 3-, and 5-year OS rate for $68 \mathrm{MPM}$ patients were $89.3 \%, 63.0 \%$, and $51.8 \%$, respectively. The

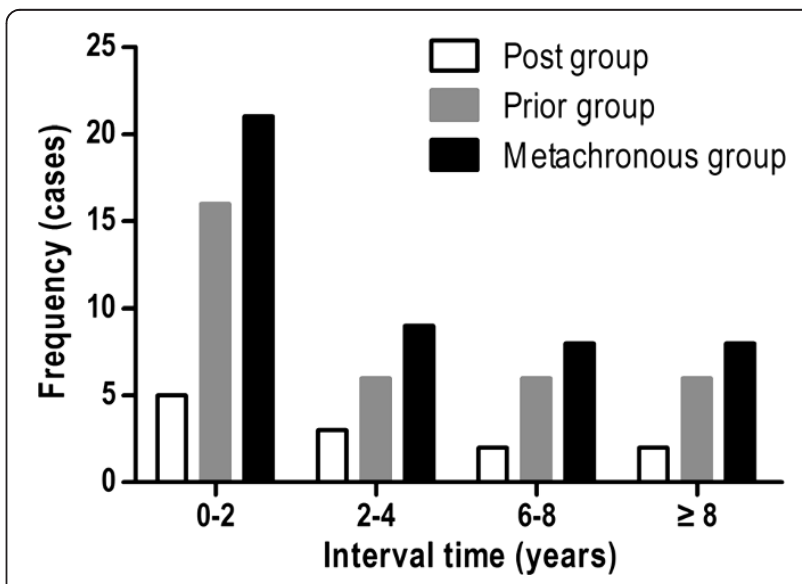

Figure 1 Schematic graph showing frequency distribution of follow-up time after diagnosis of the first primary tumor in the prior, post and metachronous groups. 
Table 2 Patient demographical characteristics of 68 multiple primary patients with hepatocellular carcinoma

\begin{tabular}{|c|c|c|c|c|}
\hline Characteristic & Total & $\begin{array}{l}\text { Synchronous } \\
\text { group }(n=22)\end{array}$ & $\begin{array}{l}\text { Metachronous } \\
\text { group }(n=46)\end{array}$ & $P$ value * \\
\hline \multicolumn{5}{|l|}{$\overline{\text { Age (years) }}^{\dagger}$} \\
\hline$<58^{\mathrm{b}}$ & 33 & 8 & 25 & 0.165 \\
\hline$\geq 58$ & 35 & 14 & 21 & \\
\hline Gender & & & & 0.514 \\
\hline Male & 61 & 21 & 40 & \\
\hline Female & 7 & 1 & 6 & \\
\hline HBsAg status & & & & 0.393 \\
\hline Negative & 23 & 9 & 14 & \\
\hline Positive & 45 & 13 & 32 & \\
\hline $\begin{array}{l}\text { Serum AFP } \\
\text { level (ng/ml) }\end{array}$ & & & & 0.085 \\
\hline$<25$ & 30 & 13 & 17 & \\
\hline$\geq 25$ & 38 & 9 & 29 & \\
\hline $\begin{array}{l}\text { Serum GGT } \\
\text { level (U/ml) }\end{array}$ & & & & 0.181 \\
\hline$<50$ & 23 & 5 & 18 & \\
\hline$\geq 50$ & 45 & 17 & 28 & \\
\hline $\begin{array}{l}\text { Child-Pugh } \\
\text { classification }\end{array}$ & & & & 0.932 \\
\hline$A$ & 49 & 16 & 33 & \\
\hline B & 19 & 6 & 13 & \\
\hline TNM stage & & & & 0.735 \\
\hline । & 43 & 14 & 29 & \\
\hline$\|$ & 9 & 2 & 7 & \\
\hline III & 16 & 6 & 10 & \\
\hline Treatment for HCC & & & & 0.309 \\
\hline Resection & 35 & 9 & 26 & \\
\hline Ablation & 7 & 3 & 4 & \\
\hline TACE & 14 & 4 & 10 & \\
\hline Supportive & 11 & 6 & 5 & \\
\hline $\begin{array}{l}\text { Treatment for } \\
\text { extrahepatic cancer }\end{array}$ & & & & $<0.001$ \\
\hline Curative & 54 & 12 & 42 & \\
\hline Palliative & 8 & 4 & 4 & \\
\hline Supportive & 6 & 6 & 0 & \\
\hline
\end{tabular}

HCC hepatocellular carcinoma, HbsAg Hepatitis B surface Antigen, AFP a-fetoprotein, GGT gamma-glutamyltransferase, TNM tumor-node-metastasis, TACE transarterial chemoembolization.

* Chi-square or Fisher's exact test.

${ }^{\dagger}$ Patients were divided according to the median age.

1-, 3-, and 5-year HCC-specific OS rate for the 35 surgical patients were $75.1 \%, 46.3 \%$, and $35.9 \%$, respectively. The difference reached significance between the metachronous and synchronous patients in OS $(P=0.008$, Figure 2), but not in HCC-specific OS $(P=0.360$, Table 3$)$.

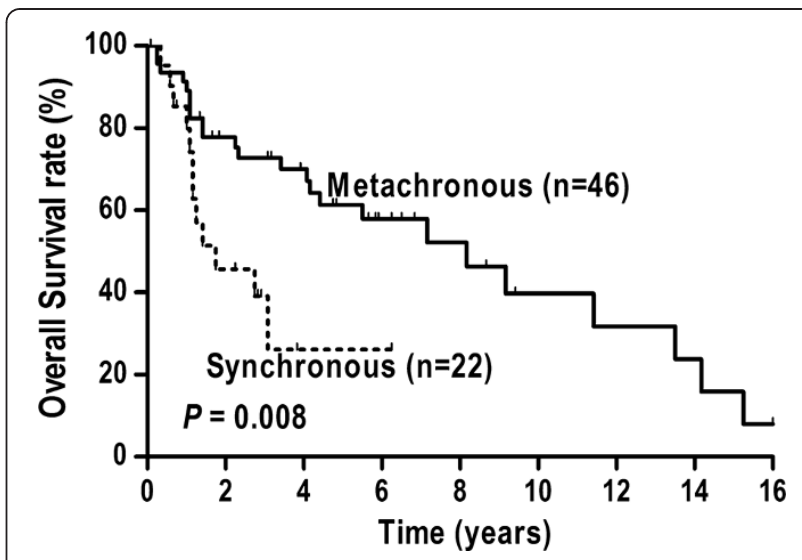

Figure 2 Comparison of Kaplan-Meier curves for overall survival between the synchronous and the metachronous groups.

The effects of clinical variables on the outcome were evaluated. Treatment options for HCC (resection), level of GGT $(\leq 50 \mathrm{U} / \mathrm{L})$ and $\operatorname{AFP}(\leq 25 \mathrm{ug} / \mathrm{L})$, tumor number (solitary), vascular invasion (absent), and TNM stage (TNM stage I) were significant factors associated with favorable HCC-specific OS in univariate analysis (Table 3). By multivariate analysis, only treatment for $\mathrm{HCC}$ remained an independent predictor of $\mathrm{HCC}$-specific OS (Table 4). Likewise, time of appearance (synchronous/ metachronous) and treatment for EHPM were strong and significant predictors of $O S$ in univariate analysis (Table 3). Finally, Cox analysis revealed the treatment for EHPM was the independent factor in OS (Table 4).

\section{Impact of EHPM on HCC-specific survival}

To investigate the impact of EHPM on survival of HCC, 140 HCC-alone randomly selected patients were included to compare with the 35 resected HCC patients with EHPM. No significant differences were found between the two groups in clinicopathological features (Table 5). Moreover, the postoperative complications were similar in two groups $(P=0.373)$, which included hemorrhage, liver failure, biliary fistula, would infection, chest infection, and cardiac arrhythmia. There was no postoperative death occurred within 30 days after resection in both groups. Median HCC-specific OS for the control, and target group were 2.54 years, and 2.56 years, respectively. There were no significant $\mathrm{HCC}$-specific OS and RFS difference between the two groups $(P=0.607$, $P=0.131$, respectively, Figure 3 ).

\section{Discussion}

The last decade has experienced a steady increase in the incidence of MPM [16]. With the expected survival of oncology patients prolonged, it is no longer rare to observe a subsequent primary malignancy in long-term 
Table 3 Univariate analysis of prognostic factors in term of overall survival and HCC-specific overall survival

\begin{tabular}{|c|c|c|c|c|c|c|}
\hline \multirow[t]{2}{*}{ Characteristic } & \multicolumn{3}{|c|}{ HCC-specific overall survival rate (\%) } & \multicolumn{3}{|c|}{ Overall survival rate (\%) } \\
\hline & $3 y$ & $5 y$ & $P$ value & $3 y$ & $5 y$ & $P$ value \\
\hline Gender & & & 0.901 & & & 0.815 \\
\hline Female $(n=7)$ & 45.5 & 38.4 & & 85.7 & 64.3 & \\
\hline Male $(n=61)$ & 51.4 & 34.3 & & 58.0 & 50.4 & \\
\hline Age (years)* & & & 0.441 & & & 0.612 \\
\hline$<58(n=33)$ & 52.3 & 47.1 & & 62.7 & 62.7 & \\
\hline$\geq 58(n=35)$ & 40.5 & 27.1 & & 59.8 & 41.7 & \\
\hline HBsAg status & & & 0.148 & & & 0.909 \\
\hline Negative $(n=23)$ & 40.0 & 28.6 & & 56.0 & 49.1 & \\
\hline Positive $(n=45)$ & 50.8 & 36.2 & & 62.4 & 51.8 & \\
\hline AFP (ug/l) & & & 0.034 & & & 0.252 \\
\hline$\leq 25(n=30)$ & 62.9 & 48.4 & & 68.9 & 68.9 & \\
\hline$>25(n=38)$ & 32.6 & 27.2 & & 54.9 & 39.6 & \\
\hline GGT level (u/l) & & & 0.040 & & & 0.073 \\
\hline$\leq 50(n=23)$ & 71.8 & 71.8 & & 76.5 & 76.5 & \\
\hline$>50(n=45)$ & 35.9 & 29.4 & & 52.9 & 43.8 & \\
\hline Cirrhosis & & & .255 & & & 0.078 \\
\hline No $(n=17)$ & 65.8 & 65.8 & & 85.6 & 66.3 & \\
\hline Yes $(n=51)$ & 40.9 & 29.5 & & 52.9 & 46.8 & \\
\hline Child-Pugh classification & & & 0.334 & & & 0.083 \\
\hline $\mathrm{A}(n=49)$ & 50.8 & 39.7 & & 64.6 & 59.8 & \\
\hline $\mathrm{B}(n=19)$ & 36.4 & 27.3 & & 48.2 & 32.8 & \\
\hline Tumor size (cm) & & & 0.865 & & & 0.537 \\
\hline$\leq 5(n=28)$ & 49.0 & 42.0 & & 62.8 & 47.3 & \\
\hline$>5(n=40)$ & 44.6 & 31.5 & & 59.7 & 48.0 & \\
\hline Multiple tumors & & & 0.001 & & & 0.221 \\
\hline No $(n=49)$ & 58.0 & 48.1 & & 65.3 & 57.7 & \\
\hline Yes $(n=19)$ & 11.1 & 11.1 & & 62.1 & 41.4 & \\
\hline Vascular invasion & & & 0.001 & & & 0.977 \\
\hline No $(n=58)$ & 51.7 & 40.2 & & 60.2 & 52.3 & \\
\hline Yes $(n=10)$ & 0 & 0 & & 66.8 & 53.4 & \\
\hline TNM stage & & & $<0.001$ & & & 0.698 \\
\hline I $(n=43)$ & 58.4 & 50.0 & & 61.4 & 54.0 & \\
\hline$\|/\| \|(n=25)$ & 17.1 & 0 & & 60.1 & 47.7 & \\
\hline Time of appearance & & & 0.360 & & & 0.008 \\
\hline Synchronous ( $n=22$ ) & 34.5 & 23.0 & & 25.7 & 25.7 & \\
\hline Metachronous $(n=46)$ & 50.3 & 40.3 & & 72.8 & 61.3 & \\
\hline Treatment for HCC & & & $<0.001^{\dagger}$ & & & 0.160 \\
\hline Resection $(n=35)$ & 71.9 & 52.0 & & 64.9 & 64.9 & \\
\hline Ablation $(n=8)$ & 50.8 & 50.8 & & 66.7 & 50.0 & \\
\hline $\operatorname{TACE}(n=14)$ & 0 & 0 & & 50.0 & 37.6 & \\
\hline Supportive $(n=11)$ & 0 & 0 & & 40.0 & 26.7 & \\
\hline Treatment for EHPM & & & 0.067 & & & $<0.001^{*}$ \\
\hline Curative $(n=54)$ & 47.3 & 33.2 & & 72.4 & 63.4 & \\
\hline
\end{tabular}


Table 3 Univariate analysis of prognostic factors in term of overall survival and HCC-specific overall survival (Continued)

\begin{tabular}{lccc}
\hline Palliative $(n=8)$ & 19.2 & 19.2 & 35.7 \\
Supportive $(n=6)$ & 11.7 & 11.7 & 0 \\
\hline
\end{tabular}

HCC: hepatocellular carcinoma, HBsAg: hepatitis B surface antigen, AFP: a-fetoprotein, GGT: gamma-glutamyltransferase, TACE: transarterial chemoembolization, EHPM: extrahepatic primary malignancy.

* Patients were divided according to the median age.

${ }^{+}$Resection vs. Ablation $P=0.346$; Ablation vs. TACE $P<0.001$; TACE vs. Supportive $P=0.413$.

* Radical vs. Palliative $P<0.001$; Palliative vs. Supportive $P=0.122$.

follow-up, especially those from therapy-related carcinogenesis $[17,18]$. A recently published paper provided by the Surveillance, Epidemiology and End Results Program estimated $7.9 \%$ of cancer-survivors were living with a history of more than one primary malignancy in the U. S [16]. The reported prevalence estimated that cancer-survivors were at an increased risk of being diagnosed with a secondary primary malignancy [19-21]. Bhatia et al. showed the risk of second tumor was increased approximately 18 times in survivors of childhood Hodgkin's lymphoma [21]. The incidence of second neoplasm in cancer-survivors $(2.3 \%, 68 / 2909)$ of our center was in accordance with previous literature [6,16,22,23], which was higher than that of the normal population [1]. We hypothesized that the improvement in early screening technologies, the advent of new molecular targeted agents, and elevated risk of carcinogenesis during the anti-cancer therapy yielded an increase prevalence of second cancer in the individuals ever diagnosed malignancy.

Several studies have demonstrated that the risk factors for poor survival of MPM patients, including male, elderly, and tumor stage [11,24]. While, our study showed no statistical difference for OS was observed in conventional clinicopathological parameters, which was agreed with other studies [5,23]. This discrepancy may be due to the different disease etiologies and heterogeneity of study populations. We believe that a study of patients from a large, multicenter, and multigeographic area would reach conclusions more powerful.
A unimodal distribution of interval time among the prior and post subgroups of the metachronous group was shown in Figure 1. Based on the time since the first cancer diagnosis, the overall risk was decreased following the first 2 years. Considering that most secondary cancers were detected by periodic examination, a postoperative periodic checkup should be performed intensively both for the prior and post groups, especially during the first 2 years. Interestingly, we found that an obvious predominance exhibited in the prior group. We hypothesized that the poor prognosis of HCC may explain partially to this circumstance [25].

Information regarding the common sites of EHMP may benefit the detection of high-risk individuals via early diagnosis, leading to improve cancer-survivor outcome. Therefore, we analyzed the frequency of EHPM according to tumor types. Contrary to our expectations drawn from the results of previous studies conducted in Japan [4] and Western countries [23], nasopharynx cancer ranked first in extrahepatic tumors, not gastric nor colorectal cancer. Nasopharyngeal carcinoma (NPC) is a disease with remarkable geographic distribution and a high incidence rate in South China. However, despite its prevalence, it does not rank first among extrahepatic tumors in South China [26]. The reasons for the high incidence of NPC in HCC patients are unclear. No apparent environmental [27] or shared genetic factors [28] explained the circumstance. In light of the high frequency of NPC in EHPM, head and neck screening (physical examination and flexible laryngoscopy) should

Table 4 Multivariate analysis of prognostic factors in term of overall survival and HCC-specific survival

\begin{tabular}{|c|c|c|c|c|}
\hline \multirow[t]{2}{*}{ Characteristic } & \multicolumn{2}{|c|}{ HCC-specific overall survival } & \multicolumn{2}{|c|}{ Overall survival } \\
\hline & $P$ value & $\mathrm{HR}(95.0 \% \mathrm{Cl})$ & $P$ value & HR $(95.0 \% \mathrm{Cl})$ \\
\hline AFP level & 0.610 & $1.257(0.522-3.030)$ & - & - \\
\hline GGT level & 0.449 & $1.485(0.534-4.130)$ & - & - \\
\hline Tumor number & 0.174 & $2.151(0.713-6.491)$ & - & - \\
\hline Vascular invasion & 0.148 & $2.550(0.717-9.064)$ & - & - \\
\hline TNM stage & 0.250 & $2.016(0.611-6.656)$ & - & - \\
\hline Treatment for HCC & 0.001 & $1.893(1.297-2.764)$ & - & - \\
\hline Time of appearance & - & - & 0.535 & $1.329(0.542-3.261)$ \\
\hline Treatment for EHPM & - & - & $<0.001$ & $2.758(1.581-4.811)$ \\
\hline
\end{tabular}

HCC: hepatocellular carcinoma, AFP: a-fetoprotein, GGT: gamma-glutamyltransferase, TNM: tumor-node-metastasis, EHPM: extrahepatic primary malignancy, HR: Hazard ratio, $\mathrm{Cl}$ : confidence interval. 
Table 5 Compared clinicalpathological features between 35 surgical HCC patients with multiple primary tumor and 140 HCC patients without extrahepatic tumor

\begin{tabular}{|c|c|c|c|}
\hline Characteristic & $\begin{array}{l}\text { Multiple } \\
\text { primarytumor } \\
\text { group }(n=35)\end{array}$ & $\begin{array}{l}\text { Control group } \\
\text { (HCC-alone) } \\
(n=140)\end{array}$ & $P$ value $^{\dagger}$ \\
\hline Age (years) * & $56.3 \pm 12.6$ & $59.1 \pm 11.2$ & $0.317^{+}$ \\
\hline Gender (Female: Male) & $5: 30$ & $30: 115$ & 0.616 \\
\hline $\begin{array}{l}\text { HBsAg (Negative: } \\
\text { Positive) }\end{array}$ & $7: 28$ & $12: 128$ & 0.101 \\
\hline $\begin{array}{l}\text { AFP level }(<25: \geq 25) \\
(\mathrm{ng} / \mathrm{ml})\end{array}$ & $17: 18$ & $44: 96$ & 0.057 \\
\hline $\begin{array}{l}\text { GGT level }(<50: \geq 50) \\
(\mathrm{U} / \mathrm{ml})\end{array}$ & $11: 24$ & $53: 87$ & 0.480 \\
\hline $\begin{array}{l}\text { Child-Pugh } \\
\text { classification (A:B) }\end{array}$ & $32: 3$ & $134: 6$ & 0.549 \\
\hline $\begin{array}{l}\text { Tumor size }(<5 \mathrm{~cm} \text { : } \\
\geq 5 \mathrm{~cm})\end{array}$ & $12: 23$ & $40: 100$ & 0.508 \\
\hline $\begin{array}{l}\text { Tumor number } \\
\text { (Solitary: Multiply) }\end{array}$ & $30: 5$ & $132: 8$ & 0.171 \\
\hline $\begin{array}{l}\text { Vascular invasion } \\
\text { (No: Yes) }\end{array}$ & $32: 3$ & $131: 9$ & 0.940 \\
\hline $\begin{array}{l}\text { Tumor capsule } \\
\text { (No: Yes) }\end{array}$ & 19:16 & $60: 80$ & 0.224 \\
\hline Cirrhosis (No: Yes) & $8: 27$ & 23:117 & 0.373 \\
\hline $\begin{array}{l}\text { Surgical margin } \\
(<2 \mathrm{~cm}: \geq 2 \mathrm{~cm})\end{array}$ & $20: 15$ & $57: 83$ & 0.080 \\
\hline TNM stage (I: II: III) & $26: 4: 5$ & $112: 18: 10$ & 0.401 \\
\hline Complication (No: Yes) & $6: 29$ & $14: 126$ & 0.373 \\
\hline
\end{tabular}

HCC: hepatocellular carcinoma, HBsAg: hepatitis B surface antigen, AFP: afetoprotein, GGT: gamma-glutamyltransferase, TNM: tumor-node-metastasis. * Mean \pm Standard Deviation

+ Chi-square test for difference between proportions (except that of Age).

* $T$ test for difference between means.

be considered in those patients. These data suggest oncologists should be aware of the risk of secondary tumor development if unexpected symptoms or signs appear, as intensive follow-up may benefit early diagnosis.

A differential diagnosis of HCC should be made, as the liver being one of the most common sites of metastases. In our cohort, $30 \mathrm{HCC}$ patients were diagnosed via standard clinical and imaging criteria combined with an elevated AFP level. The characteristic of HCC imaging in the MPMs was similar to that of $\mathrm{HCC}$-alone patients. Dynamic CT can provide useful information for the differential diagnosis for hepatic nodules [29]. A metachronous patient presented two hepatic nodules after NPC radiotherapy in this study. CT imaging showed two nodules with distinct radiologic natures (one with typical presentation of a low-density mass in the plain CT, which changed to a high-density mass in the arterial phase with relative low density in the delayed phase of dynamic CT; the other presented metastatic cancer: enhance less intensively and washout more slowly).

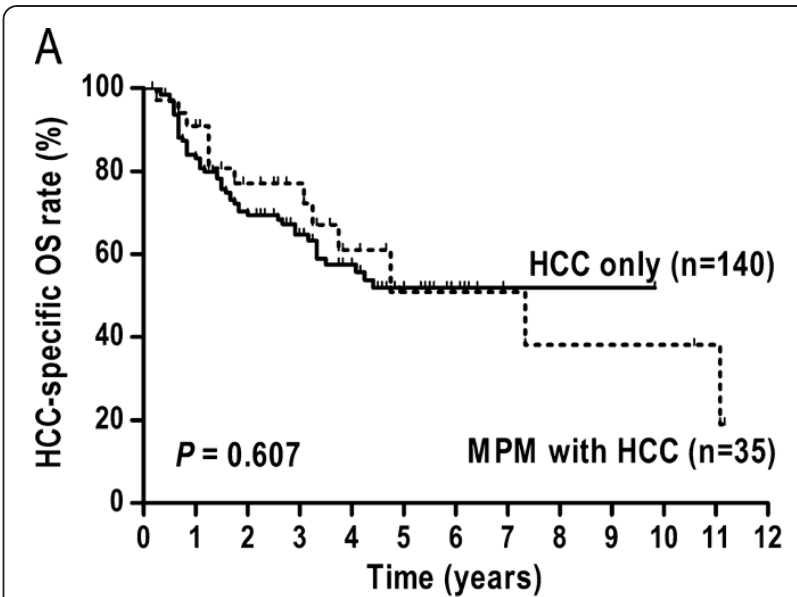

B

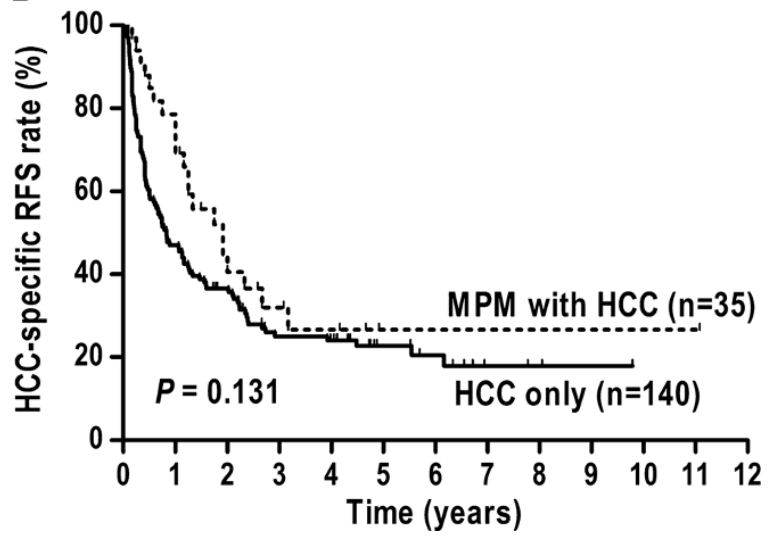

Figure 3 Comparison of Kaplan-Meier curves between the 140 HCC-alone patients and 35 multiple primary malignancies (MPM) patients with surgical HCC in term of HCC-specific overall survival (A), and HCC-specific recurrence-free survival (B).

Postoperative pathology confirmed the case suffered hepatoma complicating hepatic metastases from NPC.

We investigated whether cancer-survivors would experience poorer prognoses after second malignant neoplasm diagnosed. Our study showed that the difference of HCC-specific survival between MPM involving HCC and HCC-alone failed to reach statistical significance. This finding was similar to that reported in several cohorts [2,23], and reflected differences in the natural course of HCC compared with most associated EHPM. HCC is always associated with a poorer survival and a more aggressive behavior than most other tumors. Several cohort studies noted that the causes of death in HCC patients with EHPM were mostly attributed to $\mathrm{HCC}$ itself, not to extrahepatic cancer $[3,5]$. In light of these data, we stressed the need to prioritize curative treatment for HCC independently of the EHPM, as the presence of an EHPM had little impact on HCC-specific prognosis. While, we noticed that no significant 
difference was observed in overall survival between surgery and other therapeutic options for HCC. A longterm diagnostic interval time (median 32.4 months) from the diagnosis of the first neoplasm to the subsequent tumor presumably influenced the impact efficiency of treatment options for HCC on overall survival.

A significant difference in OS between the patients in the metachronous group and the synchronous group was not surprising. Compared with metachronous patients, synchronous patients had poorer OS. As demonstrated in Table 3, synchronous and metachronous groups associated with different treatment approaches for the extrahepatic tumor, and different treatment strategies led to distinct outcomes. Thus, we suspected that treatment modality was the final influencing factor for overall survival and built a Cox multivariate model for verification. Cox analysis confirmed it and demonstrated that treatment options for extrahepatic cancer remained as the significant factor. Therefore, an increasing effort to enlarge the proportion of patients undergoing radical treatment should been taken into account, irrespective of synchronous or metachronous tumor development.

Curative resection, if possible, most effectively prolongs patient survival. However, in cases of HCC with EHPM, the choice of treatment strategy should be made carefully in conjunction with the treatment for EHPM. There are few reports on how to treat patients with MPM involving HCC, which remains a key challenge. In our cohort, hepatectomy was an independent prognostic factor associated with good outcome. In spite of the patients that had a cirrhosis background, as experienced in our center, when patients had well-preserved liver function and when there was also an absence of extrahepatic metastasis, aggressive liver resection provided an opportunity for long-term survival.

MPM patients including HCC were often treated with supportive treatment, due to the limited therapeutic options, disappointed radical surgical rate, and poor prognosis of HCC [25]. Although several papers reported MPM concomitant with surgical HCC patients [2-5,23,24], with the small number of patients, the statistical power was limited. Of noted, only two cohort studies investigated the influence of EHPM on survival with more than 20 surgical HCC $[2,3]$. Furthermore, both of the two papers failed to refer to HCC-specific survival, which lead to decrease the value for clinical practice. We believe the present study may provide powerful evidence to make therapeutic strategy for MPM patients with HCC, which suggest those patients should not be excluded from radical resection for HCC.

Potential limitations of our study are the long time span of the observed data and the relatively small sample size, particularly with only 35 MPM patients with resected liver tumors. It would be more powerful the results from multicenter studies with larger numbers, considering the different geographic distribution of HCC. Nonetheless, the consistency of our findings with previous clinical surveys reinforces the validity of our conclusions.

\section{Conclusions}

In conclusion, NPC, colorectal, and lung cancers were the tumors most frequently accompanying HCC. Careful follow-up and active treatment is suggested for these patients. Curative treatment should been taken into account both for synchronous and metachronous patients. The efficiency of the treatment against HCC and EHPM had great influence on the prognosis. Moreover, EHPM did not confer a poorer HCC-specific survival, and those patients should not be excluded from curative therapies.

\section{Abbreviations \\ MPM: Multiple primary malignancies; EHPM: Extrahepatic primary malignancies; HCC: Hepatocellular carcinoma; OS: Overall survival; RFS: Recurrence-free survival; HBsAg: Hepatitis B surface antigen; AFP: Alpha- fetoprotein..}

\section{Acknowledgements}

This work was supported by grant of National Natural Science Foundation of China (30872489 and 30972916).

\section{Author details}

${ }^{1}$ State Key Laboratory of Oncology in South China/Department of Hepatobiliary Oncology, Sun Yat-Sen University Cancer Center, 651 Dongfeng Road East, Guangzhou, Guangdong 510060, China. ${ }^{2}$ Department of General Surgery, the Fifth Affiliated Hospital, Sun Yat-Sen University, Zhuhai, China.

\section{Competing interests}

The authors declare that they have no competing interests.

\section{Authors' contributions}

QAZ, JLQ, RHZ, YJL, SPL and YFY have made substantial contributions to conception and design of the study. QAZ, JLQ, PZH, RHZ and YZ carried out acquisition of data. JLQ, YJL, BKL and JH carried out analysis and interpretation of data. JLQ, YFY, and XML have been involved in drafting the manuscript. All authors read and approved the final manuscript.

Received: 25 September 2011 Accepted: 17 April 2012

Published: 17 April 2012

\section{References}

1. Parkin DM, Bray F, Ferlay J, Pisani P: Global cancer statistics, 2002. Ca-a Cancer Journal for Clinicians 2005, 55(2):74-108.

2. Shimada M, Takenaka K, Fujiwara Y, Gion T, Shirabe K, Nishizaki T, Yanaga K, Sugimachi K: Characteristics of hepatocellular carcinoma associated with extrahepatic primary malignancies in southern Japan. Am J Gastroenterol 1996, 91(4):754-758

3. Nzeako UC, Goodman ZD, Ishak KG: Association of hepatocellularcarcinoma in North-American patients with extrahepatic primary malignancies. Cancer 1994, 74(10):2765-2771.

4. Takayasu K, Kasugai H, Ikeya S, Muramatsu Y, Moriyama N, Makuuchi M, Yamazaki S, Hirohashi S: A clinical and radiologic study of primary liver-cancer associated with extrahepatic primary-cancer. Cancer 1992, 69(1):45-51.

5. Kanematsu M, Imaeda T, Yamawaki Y, Hirose Y, Inoue A, Goto H, Doi H: Hepatocellular-carcinoma with extrahepatic primary neoplasms. Gastrointest Radiol 1992, 17(1):53-57.

6. Lin DY, Liaw YF, Wu CS, Changchien CS, Chen PC, Chen TJ: Hepatocellularcarcinoma associated with 2nd primary malignancy. Liver 1987, 7(2):106-109. 
7. Riesz T, Jako JM, Juhasz J: Secondary malignant-tumors accompanied by primary hepatocellular carcinoma. Acta Hepato-Gastroenterologica 1979, 26(5):364-367.

8. Bosch FX, Ribes J, Diaz M, Cleries R: Primary liver cancer: worldwide incidence and trends. Gastroenterology 2004, 127(5 Suppl 1):S5-S16.

9. Jensen $\mathrm{OM}$, Storm $\mathrm{HH}$ : Cancer registration: principles and methods. Reporting of results. IARC Sci Publ 1991, 95:108-125.

10. Ecimovic P, Pompe-Kirn V: Second primary cancers in laryngeal cancer patients in Slovenia, 1961-1996. Eur J Cancer 2002, 38(9):1254-1260.

11. Aydiner A, Karadeniz A, Uygun K, Tas S, Tas F, Disci R, Topuz E: Multiple primary neoplasms at a single institution: differences between synchronous and metachronous neoplasms. Am J Clin Oncol 2000, 23(4):364-370.

12. Eom BW, Lee HJ, Yoo MW, Cho JJ, Kim WH, Yang HK, Lee KU: Synchronous and metachronous cancers in patients with gastric cancer. J Surg Oncol 2008, 98(2):106-110.

13. Tanvetyanon T, Robinson LA, Schell MJ, Strong VE, Kapoor R, Coit DG, Bepler $\mathrm{G}$ : Outcomes of adrenalectomy for isolated synchronous versus metachronous adrenal metastases in non-small-cell lung cancer: a systematic review and pooled analysis. J Clin Oncol 2008, 26(7):1142-1147.

14. Llovet JM, Burroughs A, Bruix J: Hepatocellular carcinoma. Lancet 2003, 362(9399):1907-1917.

15. Czaja AJ, Freese DK: Diagnosis and treatment of autoimmune hepatitis. Hepatology 2002, 36(2):479-497.

16. Mariotto AB, Rowland JH, Ries LA, Scoppa S, Feuer EJ: Multiple cancer prevalence: a growing challenge in long-term survivorship. Cancer Epidemiol Biomarkers Prev 2007, 16(3):566-571.

17. Guerin S, Guibout C, Shamsaldin A, Dondon MG, Diallo I, Hawkins M, Oberlin O, Hartmann O, Michon J, Le Deley MC, et al: Concomitant chemoradiotherapy and local dose of radiation as risk factors for second malignant neoplasms after solid cancer in childhood: a case-control study. Int J Cancer 2007, 120(1):96-102.

18. Allan JM, Travis LB: Mechanisms of therapy-related carcinogenesis. Nat Rev Cancer 2005, 5(12):943-955.

19. Dores GM, Metayer C, Curtis RE, Lynch CF, Clarke EA, Glimelius B, Storm H, Pukkala E, van Leeuwen FE, Holowaty EJ, et al: Second malignant neoplasms among long-term survivors of Hodgkin's disease: a population-based evaluation over 25 years. J Clin Oncol 2002, 20(16):3484-3494.

20. Lee KD, Chen SC, Chan CH, Lu CH, Chen CC, Lin JT, Chen MF, Huang SH, Yeh CM, Chen MC: Increased risk for second primary malignancies in women with breast cancer diagnosed at young age: a populationbased study in Taiwan. Cancer Epidemiol Biomarkers Prev 2008, 17 (10):2647-2655.

21. Bhatia S, Robison LL, Oberlin O, Greenberg M, Bunin G, Fossati-Bellani F, Meadows AT: Breast cancer and other second neoplasms after childhood Hodgkin's disease. N Engl J Med 1996, 334(12):745-751.

22. Chaturvedi AK, Engels EA, Gilbert ES, Chen BE, Storm H, Lynch CF, Hall P, Langmark F, Pukkala E, Kaijser M, et al: Second cancers among 104,760 survivors of cervical cancer: evaluation of long-term risk. J Natl Cancer Inst 2007, 99(21):1634-1643.

23. Fernandez-Ruiz M, Guerra-Vales JM, Castelbon-Fernandez FJ, Llenas-Garcia J, Caurcel-Diaz L, Colina-Ruizdelgado F: Multiple primary malignancies in Spanish patients with hepatocellular carcinoma: analysis of a hospitalbased tumor registry. J Gastroenterol Hepatol 2009, 24(8):1424-1430.

24. Kaczynski J, Hansson G, Wallerstedt S: Hepatocellular carcinoma and extrahepatic primary malignancy. J Hepatol 1995, 23(5):628-629.

25. Bruix J, Sherman M: Management of hepatocellular carcinoma. Hepatology 2005, 42(5):1208-1236.

26. Zhang SW, Lei ZL, Li GL, Zou LN, Zhao P, Chen WC: A report of cancer incidence and mortality from 34 cancer registries in China, 2006. Chin Cancer 2010, 19(6):356-365.

27. Jia WH, Luo XY, Feng BJ, Ruan HL, Bei JX, Liu WS, Qin HD, Feng QS, Chen $L Z$, Yao SY, et al: Traditional Cantonese diet and nasopharyngeal carcinoma risk: a large-scale case-control study in Guangdong, China. BMC Cancer 2010, 10:446.

28. Rydzanicz M, Wierzbicka M, Gajecka M, Szyfter W, Szyfter K: The impact of genetic factors on the incidence of multiple primary tumors (MPT) of the head and neck. Cancer Lett 2005, 224(2):263-278.

29. Lim JH, Choi D, Kim SH, Lee SJ, Lee WJ, Lim HK, Kim S: Detection of hepatocellular carcinoma: value of adding delayed phase imaging to dualphase helical CT. American Journal of Roentgenology 2002, 179(1):67-73. doi:10.1186/1471-2407-12-148

Cite this article as: Zeng et al:: Clinical features and outcome of multiple primary malignancies involving hepatocellular carcinoma: A long-term follow-up study. BMC Cancer 2012 12:148.

\section{Submit your next manuscript to BioMed Central and take full advantage of:}

- Convenient online submission

- Thorough peer review

- No space constraints or color figure charges

- Immediate publication on acceptance

- Inclusion in PubMed, CAS, Scopus and Google Scholar

- Research which is freely available for redistribution

Submit your manuscript at www.biomedcentral.com/submit
Ciomed Central 